\title{
Model Runtut waktu untuk Peramalan Indeks Kekeringan Daerah Lombok Utara
}

\author{
Time series model for North Lombok Drought Indices Forecasting
}

\author{
Humairo Saidah*, I. W. Yasa, Muh. Bagus Budianto, \\ Syamsul Hidayat, I.D.G Jayanegara \\ Fakultas Teknik, Universitas Mataram \\ Jl. Majapahit 62 Mataram 83125, Telp. (0370) 646506 INDONESIA
}

*corresponding author, email: h.saidah@unram.ac.id

Manuscript received: 20-11-2019. Accepted: 27-12-2019

\begin{abstract}
ABSTRAK
Model PDSI adalah metode yang memiliki akurasi yang baik untuk menghitung indeks kekeringan di Pulau Lombok. Namun metode ini hanya mampu mengevaluasi kekeringan yang telah lampau, tidak ada prosedur yang untuk memprediksi besar indeks kekeringan pada periode mendatang. Maka pembuatan model ini bertujuan untuk mengenali karakteristik kekeringan di Lombok Utara untuk keperluan mitigasi dan antisipasi dini bencana kekeringan di wilayah ini. Hasil yang diperoleh dalam penelitian ini adalah kekeringan di Lombok bagian Utara memiliki pola dengan model SARIMA $(0,1,2)(0,1,1)^{12}$. Kekeringan yang terjadi di Lombok Utara setiap tahunnya terjadi antara bulan MeiOktober dengan kecenderungan terus meningkat intensitasnya dalam 20 tahun terakhir.
\end{abstract}

Kata kunci: PDSI; SARIMA; indeks kekeringan

\begin{abstract}
PDSI is the drought index method which has good accuracy to be applied in Lombok Island. However, this method is only able to hindcast the drought without any procedure to predict the drought index in the future. So, this model aims to recognize the characteristics of drought in North Lombok for early mitigation and anticipating drought disasters purposes in this region. The results obtained from this study are that the drought pattern in North Lombok has the SARIMA model of $(0,1,2)(0,1,1)^{12}$. The drought in North Lombok mainly occurs between May-October with an increasing of drought index tends for over last 20 years.
\end{abstract}

Keyword: PDSI; SARIMA; drought index

\section{PENDAHULUAN}

Berbagai kajian mengenai perubahan iklim di dunia telah memberi bukti adanya peningkatan siklus air (Hansen et al, 2012; Trenberth, 2012), dengan kejadian ekstrim termasuk di dalamnya banjir dan kekeringan yang diperkirakan akan lebih sering terjadi (Trambauer, 
2014). Hal ini sejalan dan bahkan menguatkan kebutuhan untuk melakukan penelitian yang lebih intensif tentang keadaan ekstrim yang mungkin terjadi khususnya kekeringan demi meminimalisir kerugian baik fisik maupun non fisik.

Analisis indeks kekeringan hidrologi dapat dilakukan dengan berbagai cara seperti Standardized Precipitation Index (SPI), Palmer Drought Saverity Index (PDSI), metode Decile Indices (DI), metode Run dan lainnya. Indeks kekeringan ini diciptakan tergantung daerah penelitian, pengguna, proses, input dan output-nya dan sampai saat ini belum ada sebuah indeks kekeringan hidrologi yang berlaku secara universal (Hatmoko, 2012). Model SPI memiliki keunggulan yaitu sederhana dalam perhitungan, hanya memerlukan data hujan dan dapat menentukan tingkat keparahan kekeringan. Sedangkan model PDSI biasa dipakai untuk mengevaluasi kekeringan yang telah terjadi terutama di daerah-daerah semiarid dan yang beriklim sub-humid kering (Quiring, 2010; Turyati 1995). Model PDSI juga merupakan standarisasi untuk iklim lokal sehingga dapat digunakan untuk semua negara dalam menunjukkan kekeringan relatif atau kondisi curah hujannya (Huang et al., 2011). Metode PDSI juga bisa digunakan untuk mengkaji kekeringan dan dalam memperkirakan kekeringan (Vasiliades dan Loukas, 2009). Kedua model itu nanti akan dipakai untuk menentukan indeks kekeringan di lokasi studi dengan berbagai pertimbangannya.

Kerawanan pulau Lombok terhadap bencana kekeringan mengharuskan berbagai pihak dan utamanya para pemangku kepentingan (stakeholder) untuk mencari strategi antisipasi dan adaptasi untuk mereduksi berbagai dampak dan kerugian yang ditimbulkan. Adapun tujuan khusus dari penelitian ini adalah mendapatkan pola kekeringan yang menggambarkan karakteristik kekeringan untuk wilayah Lombok Utara sekaligus Teknik sederhana pendugaannya sesuai pola yang dihasilkan, yang nantinya dapat digunakan sebagai perangkat dalam early drought warning system. Hasil pemodelan ini juga dapat dimanfaatkan untuk pengelolaan waduk, pengaturan pola tanam, pemilihan jenis tanaman dan berbagai kebijakan pemerintah lain bagi kehidupan masyarakat di wilayah Lombok Utara.

\section{BAHAN DAN METODE}

\section{Lokasi Penelitian}

Penelitian ini mengevaluasi kekeringan yang terjadi di Kabupaten Lombok Utara yang secara geografis terletak antara $115^{\circ} 28^{\prime}$ sampai $115^{\circ} 46^{\prime}$. Wilayah Kabupaten Lombok Utara di sebelah utara berbatasan dengan laut Jawa, sebelah timur berbatasan dengan keKecamatan Sambelia Kabupaten Lombok Timur, sebelah selatan berbatasan dengan Kecamatan Gunungsari dan Narmada Kabupaten Lombok Barat serta Kecamatan Batukliang Kabupaten Lombok Tengah, dan sebelah barat berbatasan dengan Kecamatan Batu layar Kabupaten Lombok Barat 


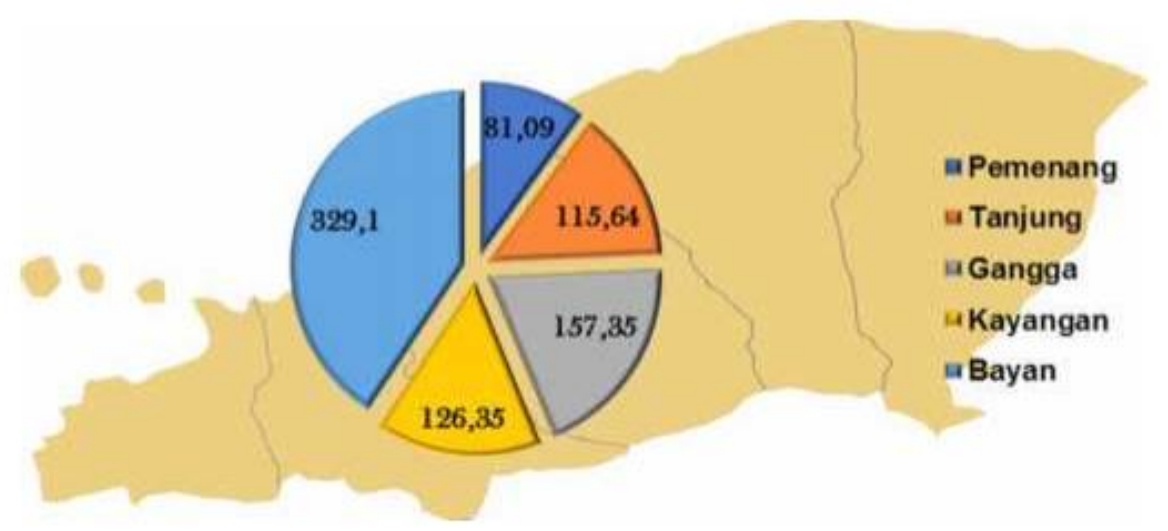

Gambar 1. Peta Kabupaten Lombok Utara (Sumber: Pemda KLU, 2017)

\section{Bahan Penelitian}

Bahan dari penelitian ini adalah berbagai data sekunder yang dikumpulkan dari instansi terkait, di antaranya adalah data hujan bulanan, data suhu udara bulanan, peta tata guna lahan, peta tekstur tanah, dan data kejadian kekeringan. Data hujan dikumpulkan untuk stasiun hujan Santong, Tanjung, Sopak dan Gunung Sari. Data suhu udara dikumpulkan dari Stasiun klimat Sopak.

\section{Metode}

Metode penelitian ini adalah metode deskriptif kuntitatif dan secara garis besar dibagi menjadi 3 tahapan pelaksanaan yaitu: pertama, pengumpulan data berupa data peta topografi, peta jenis tanah, peta penggunaan lahan, dan data hujan; kedua, pengolahan data; ketiga, pembahasan dan kesimpulan.

Pengolahan data dilakukan dengan melakukan evaluasi kekeringan di Kabupaten Lombok Utara menggunakan metode PDSI. Kemudian dilakukan analisis trend menggunakan metode statistik regresi untuk time series nilai indeks kekeringannya. Prediksi nilai Indeks Kekeringan yang akan datang didekati dengan pemodelan ARIMA. Hasil model kemudian diuji keakuratannya menggunakan nilai NRMSE dan nilai efisiensi (NSE).

\section{Analisis Indeks Kekeringan}

\section{HASIL DAN PEMBAHASAN}

Analisa indeks kekeringan PDSI dikembangkan oleh Palmer. Pada prinsipnya perhitungan nilai indeks kekeringan Palmer ini didasarkan pada besarnya curah hujan dan kemampuan tanah dalam menampung air sesuai dengan jenis tanahnya. Metode Indeks kekeringan Palmer berguna untuk mengevaluasi kekeringan yang telah terjadi terutama di daerah-daerah semiarid dan yang beriklim sub-humid kering (Ganesh dan Quiring, 2010; Turyati, 1995). Metode Palmer baik digunakan pada area yang luas dan topografi yang seragam (National Drought Mitigation Center, 2006).

Palmer menggunakan model dua lapis tanah yaitu lapisan atas dan lapisan bawah yang di dasarkan pada metode Thornthwaite (Huang et. al. 2011; Vasiliades dan Loukas, 2009). Indeks palmer didasarkan pada konsep pemasukan dan pengeluaran dari persamaan neraca air, 
yang juga dipengaruhi oleh data curah hujan dan suhu serta ketersediaan air tanah (Kao dan Govindaraju, 2010; Mishra and Singh, 2010). Salah satu alasan digunakan indeks kekeringan palmer karena indeks ini menilai kekeringan dari berbagai sumber pengamatan (Szep et.al. 2005), selain itu metode ini merupakan standarisasi untuk iklim lokal sehingga dapat digunakan untuk semua negara dalam menunjukkan kekeringan relatif atau kondisi curah hujannya (Huang et al. 2011). Metode palmer juga bisa digunakan untuk mengkaji kekeringan dan dalam memperkirakan kekeringan (Vasiliades dan Loukas, 2009).

Model PDSI membutuhkan masukan hasil perhitungan nilai evapotranspirasi potensial yang dapat dihitung dengan metode Thornthwaite Mather. Input data yang dibutuhkan adalah suhu udara rerata bulanan dan faktor penyesuaian menurut bulan dan letak lintang, dimana daerah Lombok Utara berada pada $8.3^{\circ} \mathrm{LS}$. Data suhu udara daerah Lombok Utara menunjukkan bahwa wilayah ini memiliki suhu udara rerata bulanan berkisar antara $24.5^{\circ} \mathrm{C}$ pada bulan Februri hingga $27.0^{\circ} \mathrm{C}$ pada bulan Agustus. Nilai Evapotranspirasi potensial yang dihasilkan memiliki nilai terendah sebesar $99.951 \mathrm{~mm} /$ bulan pada bulan Februari dan tertinggi terjadi pada bulan Agustus, sebesar 147.765 mm/bulan.

Analisis kapasitas tanah dalam menyimpan air (water holding capacity) yang dapat diartikan sebagai jumlah air maksimum yang dapat disimpan di dalam tanah, dimana akan tercapai jika pori-pori tanah berisi air. Pada tahap ini analisis membutuhkan data jenis tanah dan tata guna lahan untuk mendapatkan kedalaman zona perakaran berdasarkan jenis tanaman.

Tabel 1. Pendugaan jumlah air tersedia (water Holding Capacity)

\begin{tabular}{|c|c|c|c|c|c|}
\hline & Tekstur Tanah & $\begin{array}{l}\text { Air } \\
\text { Tersedia } \\
(\mathrm{mm} / \mathrm{m})\end{array}$ & $\begin{array}{c}\text { Zona } \\
\text { Perakaran (m) }\end{array}$ & $\begin{array}{r}\text { Lengas } \\
\text { Tertahan }(\mathrm{mm})\end{array}$ & Tanah \\
\hline & Tumbuhan berakar $\mathrm{d}$ & angkal & & & \\
\hline \multirow{6}{*}{ Halus } & Pasir Halus & 100 & 05 & 50 & \\
\hline & Lempung berpasir & $\begin{array}{l}100 \\
150\end{array}$ & $\begin{array}{l}0.3 \\
0.5\end{array}$ & $\begin{array}{l}30 \\
75\end{array}$ & \\
\hline & & 200 & 0.62 & 125 & \\
\hline & Lempung berdebu & 250 & 0.4 & 100 & \\
\hline & $\begin{array}{l}\text { Lempung berliat } \\
\text { Liat }\end{array}$ & 300 & 0.25 & 75 & \\
\hline & Hutan belantara tertu & & & & \\
\hline \multirow{5}{*}{ halus } & Pasir halus & 100 & 2.5 & 250 & \\
\hline & Lempung berpasir & 150 & 2.0 & 300 & \\
\hline & & 200 & 2.0 & 400 & \\
\hline & Lempung berdebu & 250 & 1.6 & 400 & \\
\hline & $\begin{array}{l}\text { Lempung berliat } \\
\text { Liat }\end{array}$ & 300 & 1.17 & 350 & \\
\hline
\end{tabular}

(Sumber: National Drought Mitigation Center, 2006)

Pendugaan nilai lengas tanah tertahan (WHC) untuk wilayah Lombok Utara didasarkan pada data tanah dan penggunaannya yang diperoleh dari peta tata guna lahan dan peta tekstur tanah (Gambar 2). Perhitungan lengkapnya disajikan pada Tabel 2. 

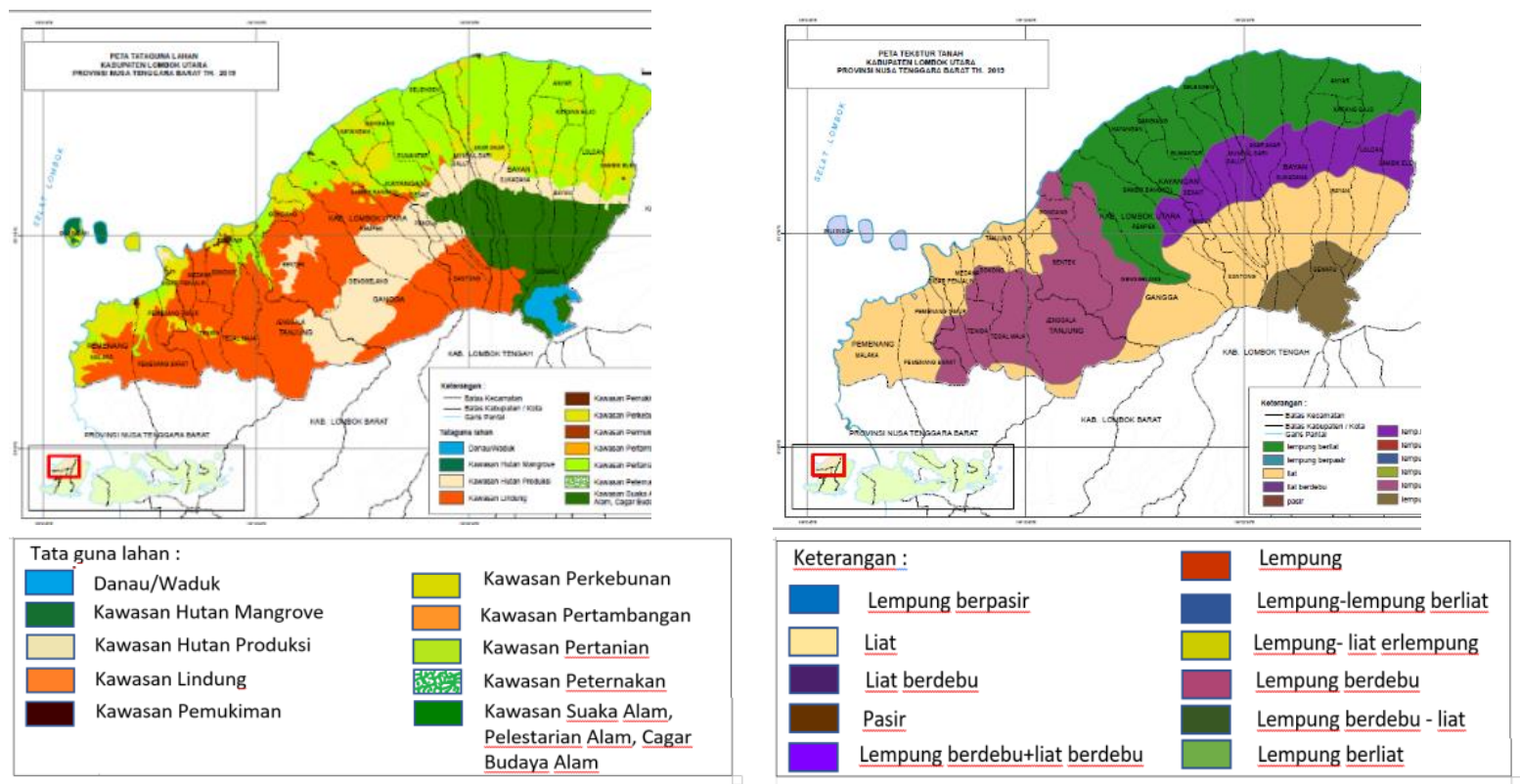

Gambar 2. Peta Tata Guna Lahan dan Peta tekstur tanah wilayah Lombok Utara Tabel 2. Pendugaan nilai WHC wilayah Lombok Utara

\begin{tabular}{lllll}
\hline \multicolumn{1}{c}{ Jenis Tanah } & Luas $\left(\mathrm{Km}^{2}\right)$ & $\begin{array}{l}\text { Zona } \\
\text { Perakaran } \\
(\mathrm{m})\end{array}$ & $\begin{array}{l}\text { Air } \\
\text { Tersedia }\end{array}$ & $\begin{array}{l}\text { Lengas } \\
\text { Tanah } \\
(\mathrm{mm})\end{array}$ \\
\hline Liat & 255.377 & 1.17 & 300 & 115.47 \\
Lempung Berliat & 212.001 & 1.6 & 250 & 109.24 \\
Lempung Berdebu & 167.099 & 2 & 200 & 86.105 \\
Lempung Berdebu-Lempung Berliat & 103.301 & 2 & 200 & 53.230 \\
lempung Berdebu-Liat & 38.471 & 2 & 200 & 19.824 \\
\hline \multicolumn{1}{c}{ Jumlah } & 776.25 & & & 383.87 \\
\hline
\end{tabular}

Setelah analisa hidrologi dan pendugaan lengas tanah, selanjutnya dapat diproses perhitungan parameter metode PDSI hingga diperoleh Indeks Kekeringan PDSI (Indeks Palmer) sebagaimana disajikan dalam bentuk grafik pada Gambar 3.

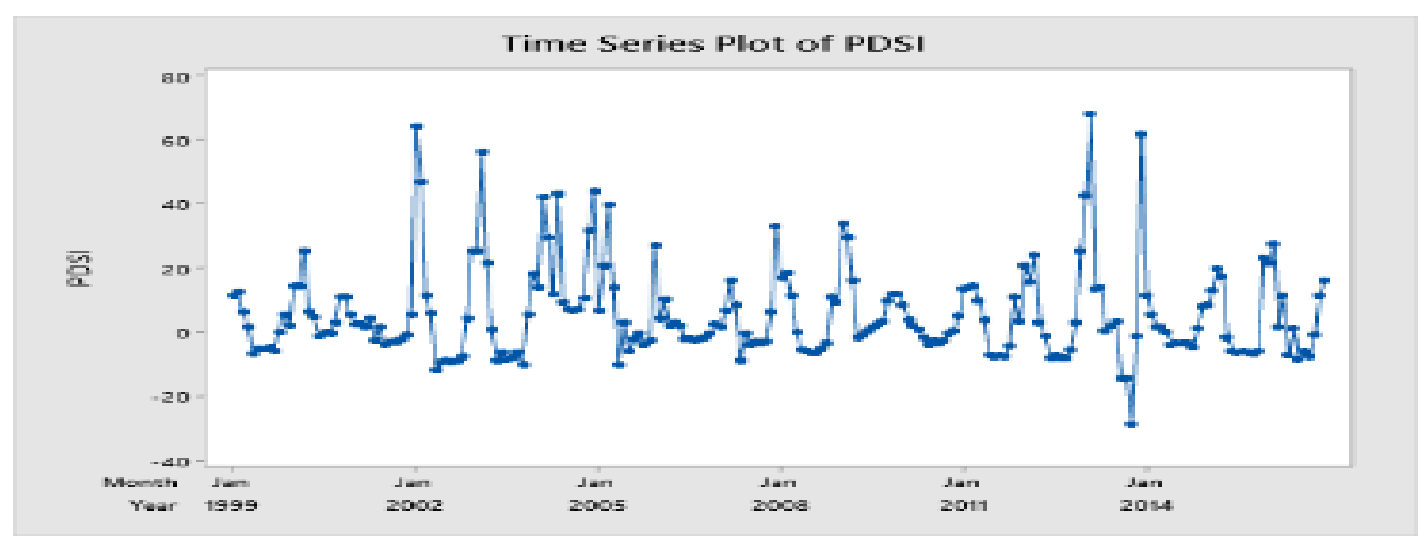

Gambar 3. Plot data Indeks Kekeringan PDSI 


\section{Peramalan Indeks Kekeringan}

Indentifikasi model runtut waktu yang tepat dilakukan dengan melihat plot data nilai Indeks PDSI yang telah didapat dan selanjutnya adalah menganalisis plot ACF dan PACF untuk menentukan pendekatan model terbaik. Plot ACF (Autocorrelation function) dan PACF (Partial Autocorrelation Function) yang disajikan pada gambar 4.

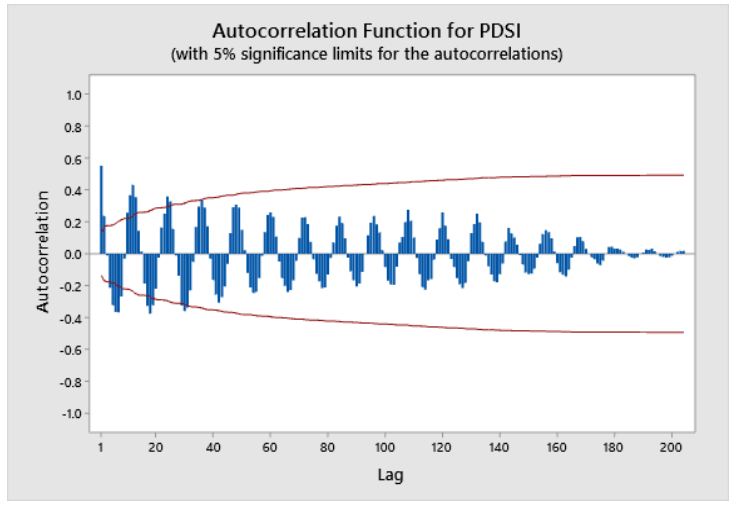

(a)

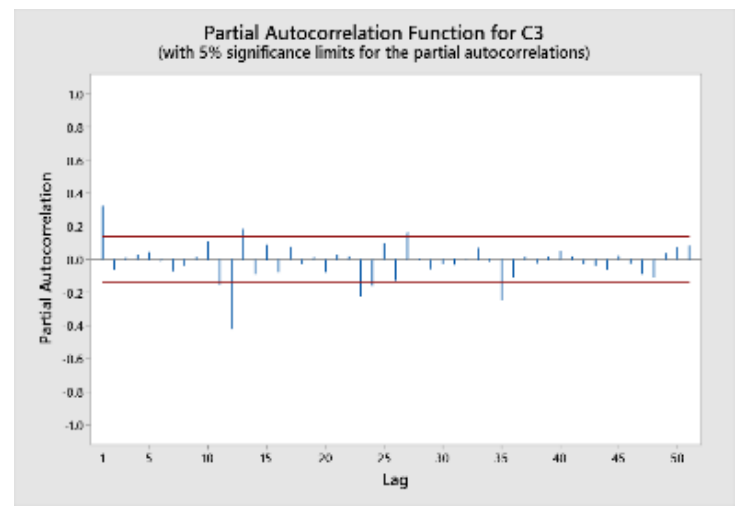

(b)

Gambar 4. Plot data nilai ACF (a) dan PACF (b)

Gambar Plot data nilai ACF PDSI di atas menunjukkan bahwa data belum stasioner, sehingga perlu dilakukan diferensiasi, berikut gambar plot hasil diferensiasi Pertama (Gambar $5)$.

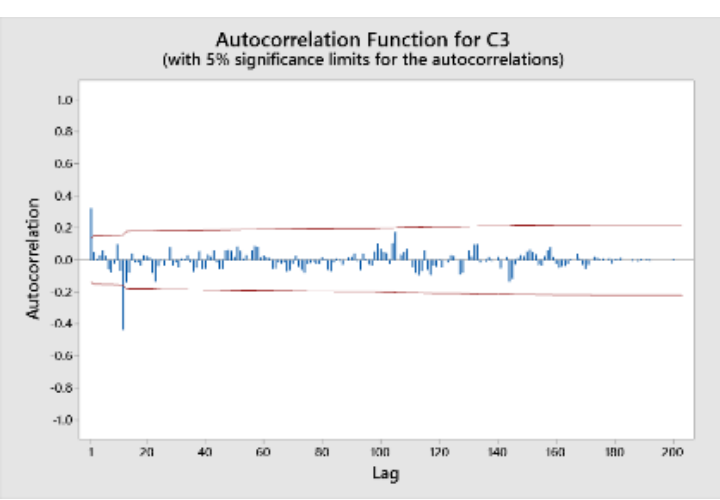

(a)

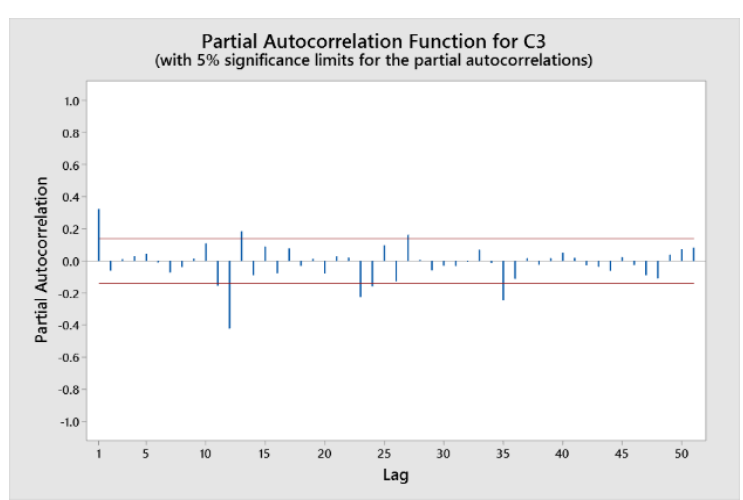

(b)

Gambar 5. Plot Nilai ACF dan PACF differencing 1

Nilai ACF PDSI Differesiasi 1 Kabupaten Lombok Utara menunjukkan bahwa plot data ACF setelah lag 1 ACF turun secara eksponensial pada rho positif dan negatif secara bergantian. Begitu juga dengan plot PACF setelah lag 1, PACF turun secara eksponensial pada positif dan negatif secara bergantian. Hal ini menunjukkan bahwa indikasi modelnya adalah model ARIMA $(1,1,2)$.

Setelah dilakukan percobaan model tentatif PDSI penggunaan peramalan metode ARIMA menghasilkan data yang bernilai positif atau negatif saja, tidak ada pola kekeringan 
yang ada, sehingga ditetapkan penggunaan metode SARIMA. Untuk model tentatif disesuaikan dengan nilai hasil ARIMA.

Tabel 3. Hasil Estimasi Parameter SARIMA

\begin{tabular}{lll}
\hline Model & MSE & Keterangan \\
\hline ARIMA $(2,2,2)(1,1,1)$ & 153,746 & $\begin{array}{l}\text { AR (1 dan 2), MA (1 dan 2) dan SMA (1) signifikan, } \\
\text { SAR (1) tidak signifikan }\end{array}$ \\
ARIMA $(0,1,2)(0,1,1)$ & 114,367 & MA (1 dan 2) signifikan SMA (1) Signifikan \\
ARIMA $(1,1,0)(0,1,1)$ & 151,138 & MA (1) signifikan dan SMA (1) signifikan \\
ARIMA $(0,1,2)(0,1,2)$ & 153,732 & $\begin{array}{l}\text { MA (1 dan 2) signifikan SMA (1) Signifikan. SMA } \\
(2) \text { tidak sigifikan }\end{array}$ \\
\hline
\end{tabular}

Berdasarkan nilai MSE yang dihasilkan dari pendugaan parameter SARIMA yang diperlihatkan pada Tabel 3, maka dapat disimpulkan bahwa model SARIMA yang terbaik untuk data PDSI adalah ARIMA $(0,1,2)(0,1,1)^{12}$ karena memiliki nilai MSE terkecil yaitu 114,367. Nilai MA (1 dan 2) signifikan SAR (1) Signifikan karena mempunyai nilai p < 0,05. Hal ini menunjukkan bahwa model dapat digunakan dengan taksiran parameter menunjukkan nilai parameter MA (1) sebesar 0,6389, MA (2) sebesar 0,3337, SMA (1) sebesar 0,9403 dan untuk konstanta sebesar -0,01231. Model peramalannya adalah sebagai berikut :

$$
\mathrm{Xt}=\mathrm{et}(1-0,6389)+(1-0,3337)+(1-0,9403)^{12}
$$

Berdasarkan model yang diperoleh, lalu dilakukan peramalan indeks kekeringan 2 tahun terakhir yaitu tahun 2017 dan 2018 dan hasilnya disajikan dalam Tabel 4 dan Gambar 6.

Tabel 4. Nilai peramalan indeks kekeringan PDSI

\begin{tabular}{lll}
\hline \multirow{2}{*}{ Bulan } & \multicolumn{2}{l}{ Nilai Peramalan Indeks PDSI } \\
\cline { 2 - 3 } & 2017 & 2018 \\
\hline Januari & 22.884 & 20.250 \\
Februari & 18.211 & 16.244 \\
Maret & 10.744 & 5.029 \\
April & 14.688 & 0.238 \\
Mei & -4.111 & -5.620 \\
Juni & -3.723 & -3.549 \\
Juli & -8.441 & -3.062 \\
Agustus & -9.244 & -2.874 \\
September & -8.265 & -2.679 \\
Oktober & -3.872 & -4.240 \\
November & 14.189 & 4.778 \\
Desember & 12.581 & -2.678 \\
\hline
\end{tabular}




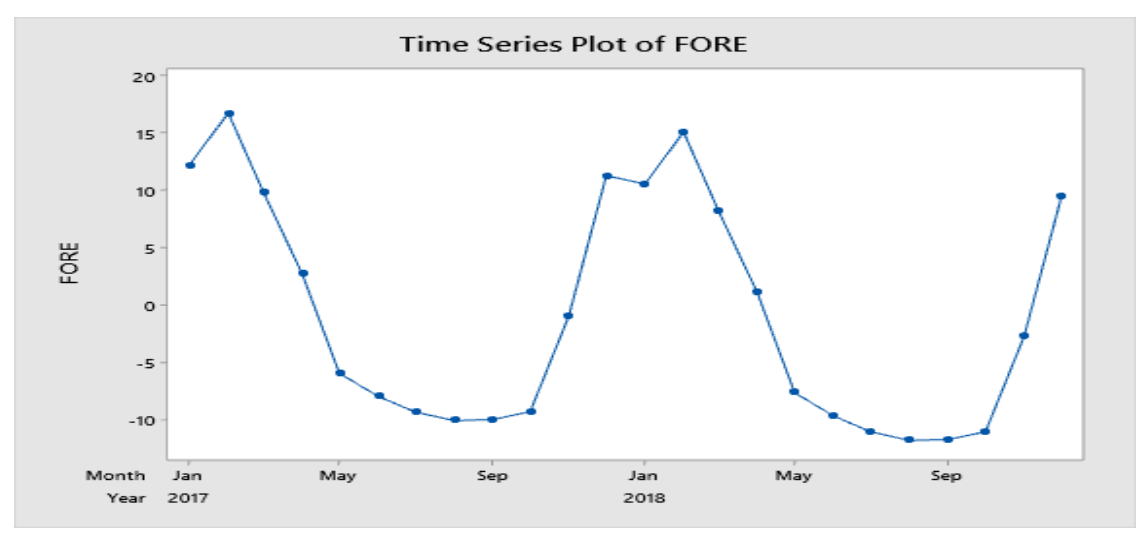

Gambar 6. Peramalan Indeks kekeringan wilayah Lombok Utara

Berdasarkan Tabel 4 dan Gambar 6 dapat dilihat bahwa peramalan Indeks kekeringan menggunakan model timeseries telah membentuk pola yang sesuai dengan bulan basah dan kering, metode PDSI cenderung bernilai negatif atau bulan kering pada bulan Mei-Oktober, hal ini dibuktikan juga pada hasil ramalan yang memiliki pola kecenderungan yang sama dengan tingkat validasi yang memenuhi syarat

\section{Pengujian akurasi model}

Kriteria akurasi model dapat menggunakan nilai normalisasi eror prediksi (Normalized Root Mean square Error, NRMSE) dan nilai efisiensi (Nash Sutcliffe Efficiency, NSE). Semakin kecil nilai RMSEP (mendekati nol) maka menunjukkan perbedaan antara nilai dugaan hasil pemodelan dengan data aktualnya semakin kecil, yang berarti makin bagus model tersebut. Sedangkan nilai efisiensi berkisar antara $-\infty$ hingga 1 . Nilai efisiensi terbaik adalah 1 , yang berarti bahwa hasil prediksi model tepat sama dengan hasil pengukuran.

$$
N R M S E=\frac{1}{\text { mean }} \sqrt{\frac{\sum_{i=1}^{n}\left(Y_{\text {pred }}-\hat{Y}_{o b s}\right)^{2}}{n}} ; \text { dan NSE }=1-\left[\frac{\sum_{i=1}^{n}\left(Y_{\text {iobs }}-Y_{\text {ipred }}\right)^{2}}{\sum_{i=1}^{n}\left(Y_{\text {iobs }}-Y_{\text {obs mean }}\right)^{2}}\right]
$$

dimana $\mathrm{Y}_{\text {pred }}=$ nilai hasil prediksi indeks kekeringan dari model SARIMA; $\mathrm{Y}_{\mathrm{obs}}=$ nilai indeks kekeringan hasil model PDSI dan hasilnya disajikan pada tabel 5.

Tabel 5. Hasil pengujian akurasi model

\begin{tabular}{ll}
\hline Parameter & Lombok Utara \\
\hline NRMSEP & 2.681 \\
NSE & -0.124 \\
\hline
\end{tabular}

Berdasarkan Penggunaan metode ARIMA diperoleh hasil peramalan yang cukup bagus jika dilihat dari nilai NRMSEP meskipun kurang bagus jika dilihat dari nilai efisiensi. Selain itu model ini juga memberikan hasil yang memuaskan jika dilihat dari pola bulan kering dan bulan basah yang dihasilkan yang sesuai dengan pola historis yang ada. 


\section{KESIMPULAN}

Model peramalan indeks kekeringan mengikuti indeks model PDSI adalah ARIMA $(0,1,2)(0,1,1)^{12}$ dengan akurasi yang cukup baik meskipun belum memuaskan secara efisiensi. Model memiliki pola kecenderungan mengikuti kecenderungan musim yang ada. Maka masih diperlukan pengkajian pemodelan yang dapat mendekati indeks kekeringan yang lebih baik menggunakan metode lain.

\section{Ucapan Terimakasih}

Peneliti mengucapkan terima kasih kepada Universitas Mataram atas dana yang diberikan melalui penelitian skim PNBP tahun 2019

\section{DAFTAR PUSTAKA}

Hansen, J., Sato, M., \& Ruedy, R. 2012. Perception of climate change. Proceedings of the National Academy of Sciences, 109(37), E2415-E2423.Hatmoko, Waluyo. 2012. Indeks Kekeringan Hidrologi untuk Alokasi Air di Indonesia. Puslitbang Sumber Daya Air. Bandung.

Huang, S., Dahal, D., Young, C., Chander, G., dan Liu, S. 2011. Integration of Palmer Drought Severity Index and Remote Sensing Data to Simulate Wetland Water Surface from 1910 to 2009 in Cottonwood Lake Area, North Dakota. Remote Sensing of Environment. Vol. 115, hal. 3377-3389

Kao, S. dan Govindaraju, R.S. 2010. A Copula-Based Joint Deficit Index for Droughts. Jurnal of Hydrology. Vol. 380. hal. 121-134

Mishra, A.K. and Singh, V.P. 2010. A Review of Drought Concepts. Journal Of Hydrology. Vol. 391, hal. 202-216.

National Drought Mitigation Center 2006. What is Drought. USA. Entry from http://drought.unl.edu/

Pemerintah Daerah Kabupaten Lombok Utara. 2017. Laporan Keterangan Pertanggungjawaban (LKJP) Tahun 2017. https://lombokutarakab.go.id/v1/9-sampledata-article/417-1kpj-2017

Quiring, S.M., and Papakryiakou, T.N., 2003. An Evaluation of Agricultural Drought Indices for the Canadian Prairies. Agricultural and Forest Meteorology. Vol. 118. hal 49-62.

Szep, I.J., Mika, J., dan Dunkel, Z. 2005. Palmer Drought Severity Index as Soil MoistureIndicator: Physical Interpretation, Statistical Behaviour and Relation to Global Climate. Physics and Chemistry of the Earth. Vol. 30. hal. 231-243.

Trambauer, P., Werner, M., Winsemius, H. C., Maskey, S., Dutra, E., and Uhlenbrook, S. 2015. Hydrological drought forecasting and skill assessment for the Limpopo River basin, southern Africa, Hydrol. Earth Syst. Sci., 19, 1695-1711.

Trenberth, K. E. 2012. Framing the way to relate climate extremes to climate change. Climatic change, 115(2), 283-290.

Turyati, A. 1995, "Sebaran Indeks Kekeringan Wilayah Jawa Barat", Skripsi, Jurusan Geofisika dan Meteorologi. Fakultas Matematika dan Ilmu Pengetahuan Alam Institut Pertanian Bogor. 
Utami, Dwi, Rr. Rintis Hadiani, Susilowati. 2013. Prediksi Kekeringan Berdasarkan Standardized Precipitation Index (SPI) Pada Daerah Aliran Sungai Keduang Di Kabupaten Wonogiri, e-Jurnal MATRIKS TEKNIK SIPIL. September 2013

Vasiliades, L. dan Loukas, A. 2009. Hydrological Response to Meteorological Drought Using the Palmer Drought Indices in Thessaly, Greece. Desalination. Vol. 237, hal. 3-21. 